\title{
PERANCANGAN SISTEM INFORMASI DAN PENDATAAN IKATAN PELAJAR MAHASISWA SUMBAWA- YOGYAKARTA (IPMSY) BERBASIS WEB
}

\author{
Ryan Suarantalla \\ Program Studi Teknik Industri, Fakultas Teknik Pertambangan, Universitas Teknologi Sumbawa \\ ryan.suarantalla@gmail.com
}

\begin{abstract}
ABSTRAK
Mahasiswa (Pelajar) Sumbawa yang melanjutkan kuliah di Yogyakarta tiap tahun semakin meningkat. Hal ini menyebabkan pelajar-pelajar tersebut kesulitan untuk memperoleh berbagai informasi, baik informasi tentang data mahasiswa yang berasal dari Sumbawa, informasi di bidang akademik, maupun informasi kegiatan-kegiatan sosial. Permasalahan tersebut dapat dianalisis dengan metode PIECES (Performance, Information, Economy, Control, Eficiency, dan Services). Untuk mempermudah dalam mendapatkan data mahasiswa dan menyampaikan informasi dari berbagai lokasi dirancang suatu sistem online berbasis website. Websitetersebut dirancang dengan menggunakan software perancangan seperti Adobe Photoshop CS3 dan Macromedia dreamweaver 8. Sedangkan untuk membuat web server (Apache) menggunakan XAMPP versi 1.7.3. Selain itu, website ini juga dilengkapi dengan menu-menu, seperti informasi agenda mahasiswa, berita, dan galeri. Dari konsep ini maka sistem mempunyai kelebihan dalam memberikan suatu informasi dan melakukan pendataan bagi mahasiswa Sumbawa yang berada di Yogyakarta.
\end{abstract}

Kata Kunci: IPMSY Yogyakarta, Sistem Informasi, Pendataan, Mahasiswa, website.

\section{PENDAHULUAN}

Website pada saat ini telah menjadi trend dalam dunia internet dan telah menjadi kebutuhan masyarakat di bidang teknologi dalam mendapatkan informasi yang lebih cepat dan akurat. Adanya internet telah mengubah pola hidup masyarakat dalam kehidupan bersosial. Salah satu yang menarik adalah pendataan dan penyebaran informasi secara online. Dalam pembuatan website perlu dilakukan pengumpulan data yang benar dan adanya suatu pemahaman sistem kerja yang sesuai prosedur, agar aplikasi yang dibuat memiliki data yang akurat. Selain itu, website juga menjadi solusi dalam dunia internet dan telah menjadi kebutuhan masyarakat di bidang teknologi dalam mendapatkan informasi yang lebih cepat, tepat, dan akurat. Termasuk salah satunya dikalangan mahasiswa Sumbawa yang melanjutkan pendidikan di Yogyakarta.

Ikatan Pelajar Mahasiswa Sumbawa Yogyakarta (IPMSY) merupakan sebuah organisasi yang dibentuk sebagai wadah pemersatu dan silaturahmi antar mahasiswa se-Kabupaten Sumbawa yang menempuh studi di kota pelajar Yogyakarta. Setiap tahun mahasiswa Sumbawa yang melanjutkan kuliah di Yogyakarta semakin meningkat.
Akan tetapi, ketika ada mahasiswa baru yang ingin mengetahui keberadaan teman satu daerah seringkali menemui kesulitan dikarenakan masih minimnya informasi yang dimiliki terutama tentang lokasi di mana mereka tinggal sekarang. Selain itu organisasi mahasiswa Sumbawa yang ada di Yogyakarta masih mengalami kesulitan untuk mendata dan memberikan informasi kepada mahasiswa yang berasal dari Sumbawa. Berdasarkan permasalahan tersebut, diperlukan sebuah website untuk mempermudah melakukan pendataan terhadap mahasiswa Sumbawa dan mengetahui informasi dari Ikatan Pelajar Mahasiswa Sumbawa Yogyakarta (IPMSY) sehingga dapat mengoptimalkan kinerja dari Ikatan Pelajar Mahasiswa Sumbawa Yogyakarta (IPMSY).

Sistem informasi adalah suatu sistem di dalam suatu organisasi yang mempertemukan kebutuhan pengolahan transaksi harian, mendukung operasi, bersifat manajerial dan kegiatan strategi dari suatu organisasi dan menyediakan pihak luar tertentu dengan laporan - laporan yang diperlukan (Jogiyanto, 1999). Informasi merupakan data yang diolah menjadi bentuk yang lebih berguna dan lebih berarti bagi 
yang menerimanya. Sumber dari informasi adalah data. Data merupakan bentuk jamak dari bentuk data item yang menggambarkan suatu kejadian - kejadian suatu dan kesatuan nyata. Data diolah melalui suatu model menjadi informasi, penerima kemudian menerima informasi tersebut serta membuat suatu keputusan dan melakukan tindakan yang berarti menghasilkan suatu tindakan yang lain akan membuat sejumlah data kembali. Data tersebut akan ditangkap sebagai input, diproses kembali lewat suatu model dan seterusnya membentuk suatu siklus. (Jogiyanto,1999). Siklus ini disebut dengan siklus informasi (Information cycle) atau siklus pengolahan data (data processing cycles) (Gambar 1).

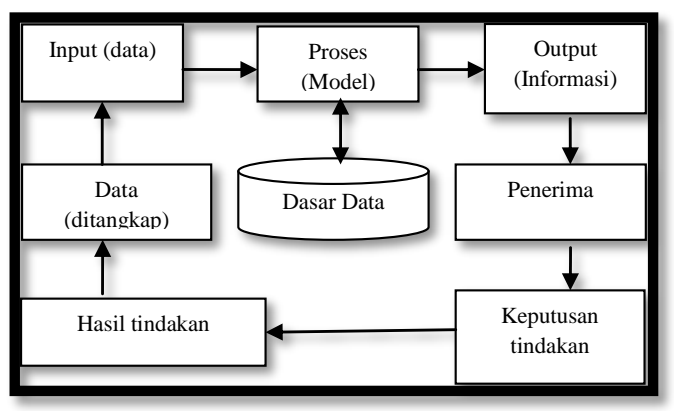

Gambar 1. Siklus Informasi Sumber: (Tata Sutabri, 2005)

Kualitas dari suatu informasi (quality of information) tergantung pada tiga hal yaitu (Jogiyanto, 1999):

1. Akurat: Informasi harus akurat karena dari sumber informasi sampai ke penerima kemungkinan terjadi gangguan (noise) yang dapat merubah atau merusak informasi tersebut.

2. Tepat pada waktunya: Informasi yang datang ke penerima tidak boleh terlambat, karena informasi yang sudah usang tidak akan mempunyai nilai lagi.

3. Relevan: Relevansi berarti informasi tersebut mempunyai manfaat untuk pemakaiannya.

Dalam membangun dan merancang sebuah website diperlukan bahasa pemrograman web dan beberapa software seperti:

\section{a. PHP (Hypertext Preprocessor)}

PHP adalah bahasa server-side scripting yang menyatu dengan $H T M L$ untuk membuat halaman web yang dinamis. Maksud dari server-side scripting, yaitu sintaks dan perintah-perintah yang diberikan akan sepenuhnya dijalankan di server, tetapi disertakan dokumen HTML (Arief, 2011).

Pembuatan web ini merupakan kombinasi antara $P H P$ sendiri sebagai bahasa pemrograman dan HTML sebagai pembangun halaman web.

\section{b. MySQL}

MYSQL adalah multiuser database yang menggunakan bahasa Structured Query Language (SQL). MySQL mampu menangani data yang cukup besar. SQL adalah bahasa standar yang digunakanuntuk mengakses database server (Arief, 2011). Dengan SQL, proses akses database menjadi lebih user-friendly dibandingkan dengan menggunakan dBase atau Clipper yang masih menggunakan perintah-perintah pemrograman.

\section{c. $\quad$ DDL (Data Definition Language)}

Merupakan kelompok perintah untuk mendefinisikan atribute - atribute database, seperti tabel, record, batasan nilai atribut dan relasi antar table (Arief, 2006). Pernyataanpernyataan yang termasuk kelompok ini antara lain:

- CREATE: Perintah ini digunakan untuk membuat, termasuk diantaranya membuat database baru, tabel baru, view baru, dan kolom.

- ALTER: Perintah ini digunakan untuk mengubah struktur tabel yang telah dibuat. Pekerjaannya mencakup mengganti nama tabel, menambah kolom, mengubah kolom, menghapus kolom, maupun memberikan atribut pada kolom.

- DROP: Perintah ini digunakan untuk menghapus database dan tabel. 


\section{d. DML (Data Manipulation Language)}

Data Manipulation Language (DML) merupakan sub bahasa $S Q L$ yang digunakan untuk memanipulasi data dalam database yang telah terbuat (Arief, 2006). Perintah yang digunakan, diantaranya:

- INSERT: perintah ini digunakan untuk menyisipkan atau memasukkan data baru ke dalam tabel. Penggunaannya setelah database dan tabel selesai dibuat.

- SELECT: Perintah ini digunakan untuk mengambil data atau menampilkan data dari satu tabel atau beberapa tabel dalam relasi. Data yang diambil dapat kita tampilkan dalam layar prompt MySQL secara langsung maupun ditampilkan pada tampilan aplikasi.

- UPDATE: Perintah ini digunakan untuk memperbaharui data lama menjadi data terkini. Jika anda memiliki data yang salah atau kurang Up To Date dengan kondisi sekarang, maka dapat diubah isi datanya dengan menggunakan perintah UPDATE.

- DELETE: Perintah ini digunakan untuk menghapus data dari tabel. Biasanya data yang dihapus adalah data yang tidak diperlukan lagi. Pada saat menghapus data, perintah yang telah dijalankan tidak dapat digagalkan, sehingga data yang telah hilang tidak dapat dikembalikan lagi.

\section{e. Macromedia Dreamweaver}

Macromedia Dreamweaver merupakan suatu bentuk perangkat lunak editor web yang dibuat oleh Macromedia. Dengan program ini, seorang programer web dapat dengan mudah membuat dan mendesain web. Dreamweaver adalah editor yang lengkap digunakan untuk membuat animasi sederhana yang berbentuk layer.

Sebagai editor, dreamweaver MX mempunyai sifat yang WYSIWYG (what you see is what you get), artinya apa yang kamu lihat akan kamu peroleh. Dengan kelebihan ini, seorang programer dapat langsung melihat hasil buatannya tanpa harus membuka browser. Seperti program editoreditor lainnya, Dreamweaver $M X$ juga memiliki dua bentuk layer, yaitu bentuk halaman design dan halaman code (Madcoms, 2010). Hal ini akan mempermudah dalam menambahkan script berbasis PHP maupun Javascript. Dreamweaver selain mendukung pembuatan web yang berbasis $H T M L$, juga mendukung program-program webyang lain, seperti PHP, ASP, Perl, Javascript dan lainlain.

\section{f. Apache}

Web server adalah komputer yang digunakan untuk menyimpan dokumendokumen web, komputer server ini akan melayani permintaan dokumen dari clientnya. Web server diperlukan agar fungsifungsi server pada halaman web yang menggunakan server side scripting yang ada pada halaman tersebut dapat dieksekusi dan ditampilkan pada browser (Abdul Kadir, 2005).

\section{g. DFD (Data Flow Diagram)}

Data Flow Diagram adalah suatu model logika data atau proses yang dibuat untuk menggambarkan darimana asal data dan kemana tujuan data yang keluar dari sistem, dimana data tersimpan, proses apa yang menghasilkan data tersebut dan interaksi antara data yang tersimpan dan proses yang dikenakan pada data tersebut (Jogiyanto, 1999).

Elemen - elemen yang menyusun suatu $D F D$, yaitu:

1. Proses: Aktivitas atau fungsi yang dilakukan untuk alasan bisnis yang spesifik, berupa manual maupun komputerisasi.

2. Data Flow: Satu data tunggal atau kumpulan logis suatu data, selalu diawali atau berakhir pada suatu proses.

3. Data Store: Kumpulan data yang disimpan dengan cara tertentu dan disimpan dalam data store.

4. External Entity: Orang, organisasi, atau sistem yang berada di luar sistem tetapi berinteraksi dengan sistem.

\section{h. ERD (Entity Relationship Diagram)}

Entity Relationship Diagram adalah nama lain dari Database Modeling yang mendeskripsikan hubungan antara entitas satu dengan entitas yang lainnya. Terdapat 
tiga notasi yang bekerja pada model E-R, yaitu: entity sets, relationalship shets, dan attributes (Jogiyanto, 1999). Sebuah entity adalah sebuah benda (thing) atau objek (object) didunia nyata yang dapat dibedakan dari semua objek lainnya.

\section{ANALISIS DAN PERANCANGAN SISTEM Analisis PIECES}

Untuk mengidentifikasi masalah, harus dilakukan analisis terhadap kinerja, informasi, ekonomi, keamanan aplikasi, efisiensi, dan pelayanan pelanggan. Panduan ini dikenal dengan analisis PIECES (Performance, Information, Economy, Control, Eficiency, dan Services) (Hanif Al Fatta, 2007).

\section{Analisis Kinerja (Performance)}

Kinerja atau Performance adalah suatu kemampuan sistem dalam menyelesaikan tugas dengan cepat sehingga sasaran dapat segera tercapai (Hanif Al Fatta, 2007). Kinerja (Performance) diukur dengan parameter jumlah produksi dan waktu tanggap. Hasil analisis dari paramater jumlah produksi (Throughput) yaitu untuk menyampaikan informasi dan pendataan masih menggunakan cara manual sehingga memerlukan waktu lama, serta waktu tanggap (respontime) yaitu ketika terjadi kendala data informasi dan data mahasiswa hilang atau rusak, maka dibutuhkan waktu lebih lama lagi untuk mengumpulkannya.

\section{Analisis Informasi (Information)}

Informasi merupakan komoditas krusial bagi pengguna terakhir (Hanif Al Fatta, 2007). Pada organisasi IPMSY masih terdapat beberapa situasi yang membutuhkan peningkatan kualitas dan kecepatan dalam hal pengolahan informasi. informasi (information) diukur dengan parameter tingkat keakuratan, timeline, dan relevansi. Hasil analisis dari parameter akurat yaitu jika terjadi kesalahan informasi dan data mahasiswa, maka kesalahan tidak bisa langsung di revisi sehingga yang diterima tidak sesuai, sedangkan timeline yaitu Perubahan informasi dan data mahasiswa tidak bisa langsung diketahui, sehingga informasi dan data yang diterima terlambat, serta Informasi kurang relevan jika diterima oleh pihak yang tidak membutuhkan.

\section{Analisis Ekonomi (Economy)}

Penilaian sistem dalam penghematan dan keuntungan yang akan didapat dari sistem yang dikembangkan (Hanif Al Fatta, 2007). Sistem ini akan memberikan penghematan operasional dan meningkatkan keuntungan operasi. Penghematan didapat melalui pengurangan bahan baku dan perawatan. Sementara keuntungan didapatkan dari peningkatan nilai informasi dan keputusan yang dihasilkan. Analisis ekonomi di ukur dengan parameter biaya yang dikeluarkan serta manfaat yang diberikan. Hasil analisis dari parameter biaya yaitu biaya yang dikeluarkan banyak untuk membuat brosur atau pamplet serta dalam melakukan pendataan masih harus menemui langsung pengurus, sedangkan manfaatnya masih kurang karena terbatasnya biaya untuk membuat brosur atau pamflet dan pendataan mahasiswa membutuhkan biaya transportasi yang tidak sedikit.

\section{Analisis Pengendalian (Contro)}

Pengendalian (contro) sangat diperlukan keberadaannya untuk menghindari dan mendeteksi secara dini terhadap penyalahgunaan atau kesalahan sistem serta untuk menjamin keamanan dan informasi, dengan adanya kontrol maka tugas-tugas atau kinerja yang mengalami gangguan dapat diperbaiki (Hanif Al Fatta, 2007). Pengolahan data lebih aman karena tersimpan dalam database server dan sistem memakai password dan tidak ada kesamaan data dalam file karena dibatasi oleh sistem. Pengendalian (control) diukur dengan parameter Pengaturan manajemen data informasi dan pengamanan data. Hasil analisis dari paramater Pengaturan manajemen data informasi yaitu Kurangnya manajemen pengaturan informasi dan pengaturan data mahasiswa, akibatnya informasi dan pendataan tidak maksimal, sedangkan, pengamanan data yaitu Tidak adanya keamanan data, jika data diambil orang atau hilang maka akan menyulitkan pengurus organisasi.

\section{Analisis Efisiensi (Efficiency)}

Efisiensi berhubungan dengan sumber daya yang ada guna meminimalkan pemborosan. Efisiensi dari sistem yang dikembangkan adalah pemakaian secara 
maksimal atas sumber daya yang tersedia yang meliputi manusia, informasi, waktu, uang, peralatan, ruang, dan keterlambatan pengolahan data (Hanif Al Fatta, 2007). Efisiensi diukur dengan parameter pengguna sumber daya dan hasil yang didapat. Hasil dari parameter pengguna sumber daya yaitu menunjukan bahwa kinerja organisasi yang telah berjalan selama ini masih menggunakan cara manual sehingga terjadi pemborosan waktu, tenaga dan biaya, Sedangkan hasil yang didapat yaitu dalam penggunaan sistem masih secara manual, menyebabkan waktu kerja yang relatif lama dan tidak efisien.

\section{Analisis Layanan (services)}

Perkembangan informasi dipicu peningkatan pelayanan yang lebih baik. Peningkatan pelayanan terhadap sistem yang dikembangkan akan memberikan sistem yang mudah dipakai (Hanif Al Fatta, 2007). Pelayanan (Services) diukur dengan parameter ragam informasi dan kemudahan mendapat informasi. Hasil analisis dari parameter Ragam informasi yaitu masih menggunakan cara manual, jadi ragam informasi yang diterima masih kurang maksimal, sedangkan kemudahan mendapat informasi yaitu untuk mendapatkan informasi selama masih menggunakan sistem yang lama, masih sulit karena terbatasnya ragam informasi yang disajikan.

\section{Analisis Kebutuhan Sistem}

Untuk mempermudah analisis sistem dalam menentukan keseluruhan kebutuhan secara lengkap, maka analisis membagi kebutuhan sistem kedalam 2 jenis, yaitu:

a. Kebutuhan Perangkat Keras (Hardware)

Analisis perangkat keras bertujuan untuk mengetahui secara tepat perangkat keras yang dibutuhkan. Adapun hardware yang digunakan penulis dalam mengembangkan sistem informasi ini adalah:

- Prosessor : Intel (R) Pentium (R) DualCPUT2410@2.00GHz

- RAM:2GBDDR2

- VGA : SIS Mirage 3 up to $256 \mathrm{Mb}$, Support Microsoft $\circledast$ Direct $X ® 9.0$

- Hardisk : SATA Seagate 160GB

- Perangkat input dan Output. b. Kebutuhan perangkat lunak (software)

1) Software untuk perancangan

- Adobe Photoshop CS3, software tersebut digunakan untuk kebutuhan pengelolah gambar dan grafik.

- Macromedia dreamweaver 8, digunakan untuk membuat script pemrograman web.

2) Software untuk web server (Apache)

$X A M P P$ versi 1.7.3 web yang didalamnya terintegrasi Apache dan MySQL. Apache digunakan untuk mengatur dan melayani pengiriman dokumen.

\section{Perancangan Sistem}

Tujuan dari perancangan sistem secara umum adalah untuk memberikan gambaran secara umum pada user atau pengguna tentang sistem yang baru atau sistem yang diusulkan (Hanif Al Fatta, 2007). Perancangan sistem secara umum mengidentifikasikan komponen sistem informasi yang akan didesain secara rinci.

\section{Perancangan Data Flow Diagram (DFD)}

DFD yang diusulkan pada website organisasi IPMSY dapat dilihat pada Gambar 2 dan Gambar 3.

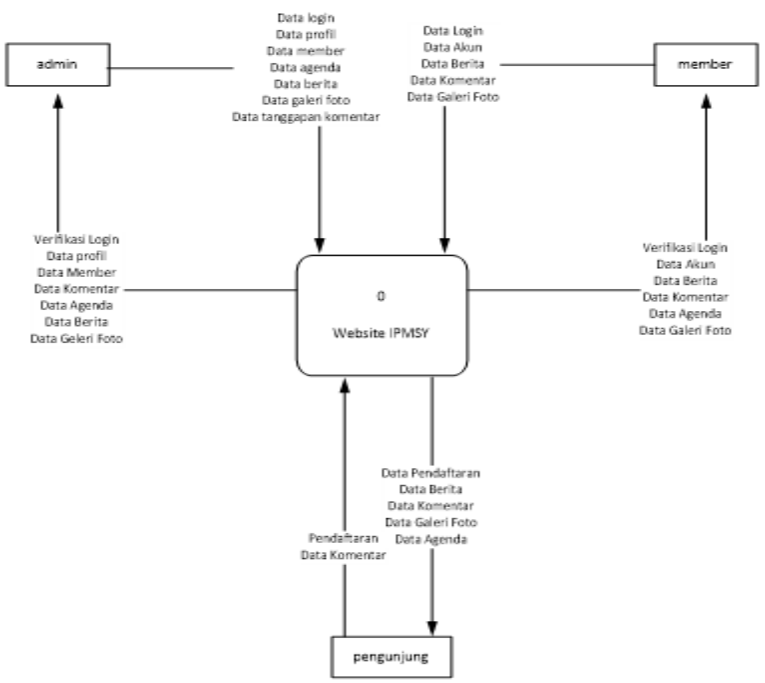

Gambar 2. DFD Level 0 


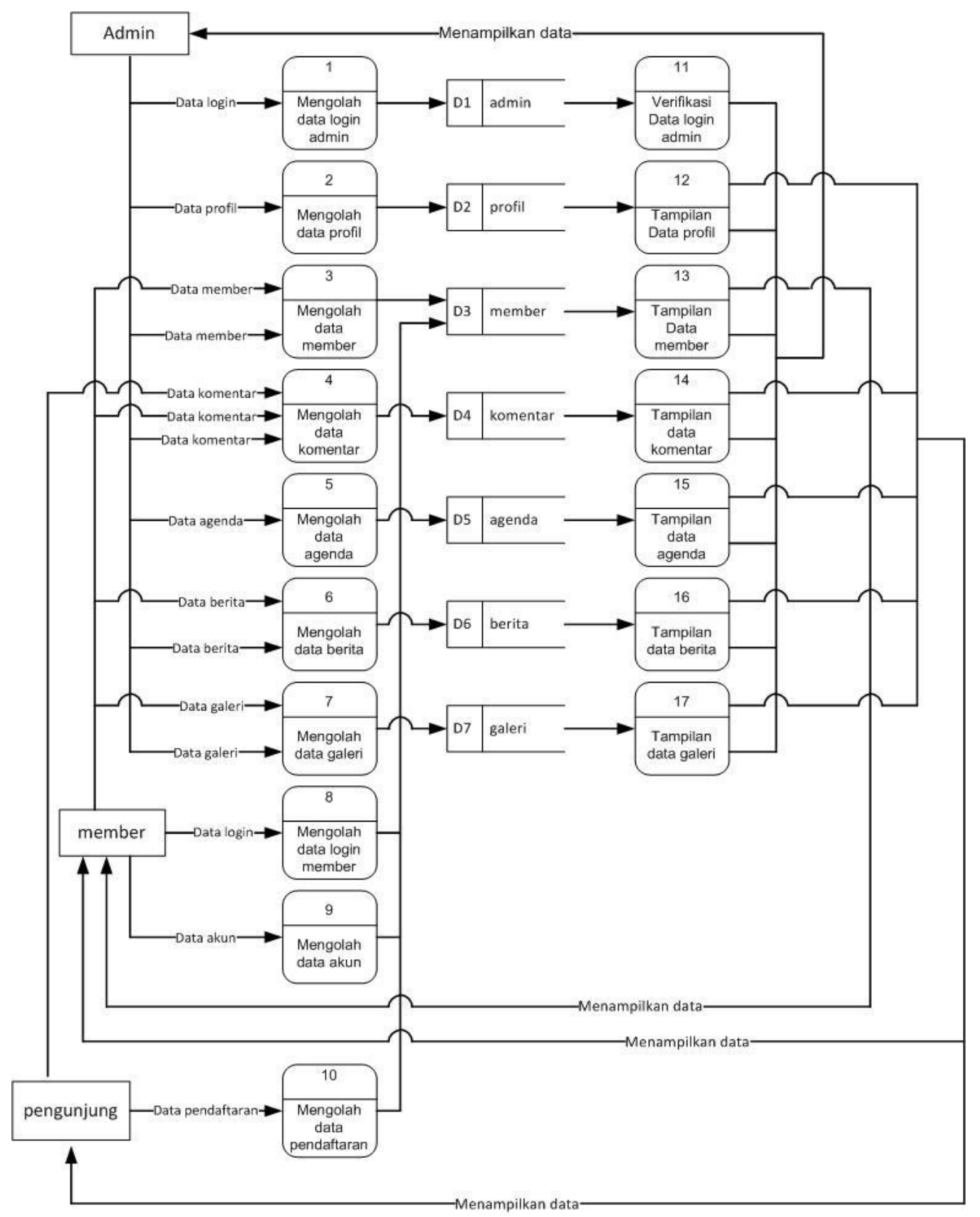

Gambar 3. DFD Level 1

Perancangan Basis data

Perancangan Entity Relationship

Diagram (ERD)

ERD yang diusulkan pada website

IPMSY diperlihatkan oleh Gambar 4.
Sementara itu, tabel-tabel yang terdapat dalam data base website ditunjukkan oleh Gambar 5. 


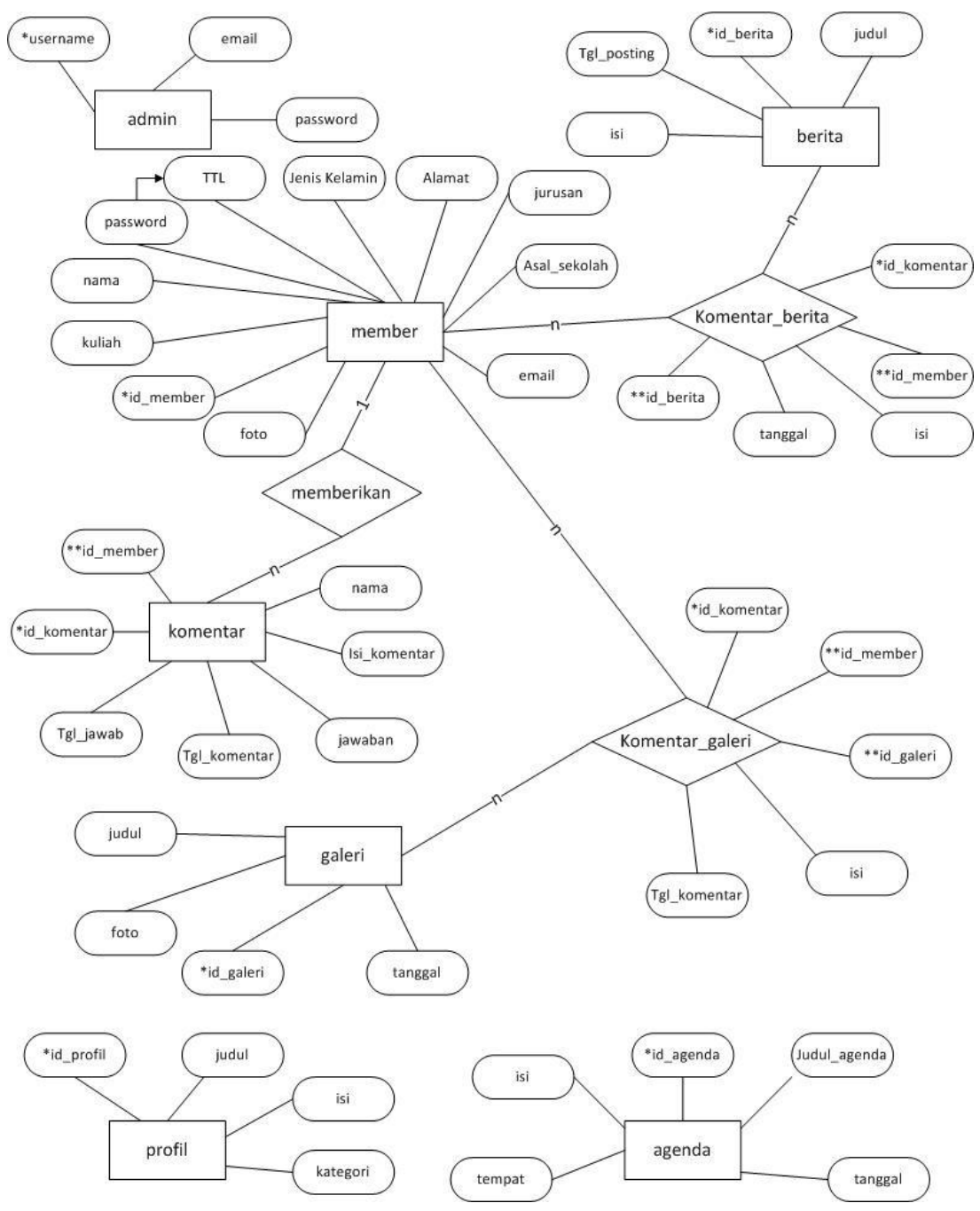

Gambar 4. ERD

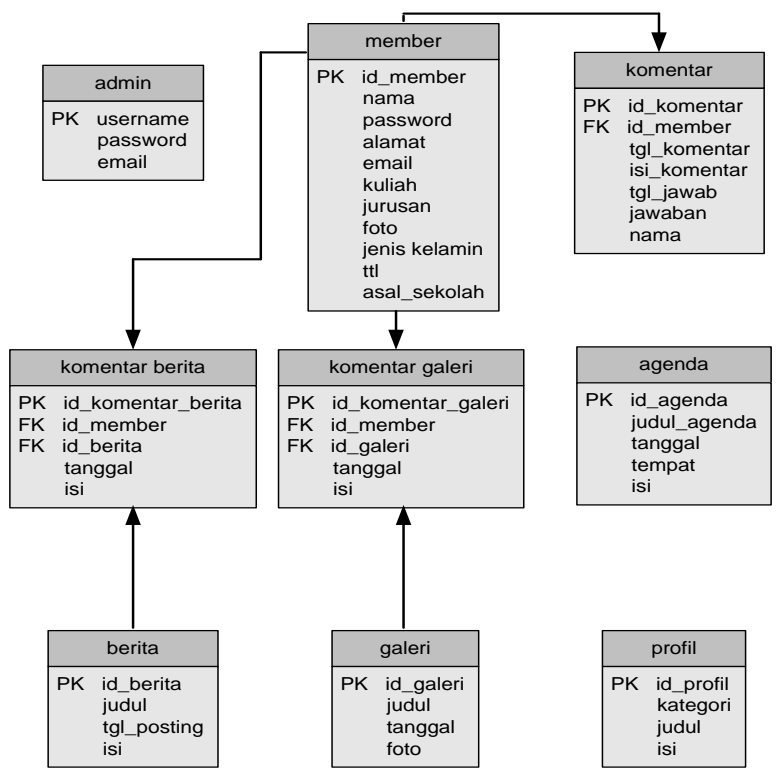

Gambar 5. Relasi Antar Tabel 


\section{Perancangan Interface}

Sistem informasi IPMSY berbasis web dirancang dengan beberapa interface, seperti halaman admin, member, pengunjung, dan halaman daftar.

\section{Halaman Admin}

Halaman ini berisi tentang informasi dari database yang membangun website. Untuk mengakses halaman ini administrator harus harus tetap login terlebih dahulu dengan mengetikkan user dan password.

\section{Halaman Login Admin}

Halaman login digunakan untuk melakukan login admin sehingga bisa masuk ke halaman admin. Rancangan halaman login admin diperlihatkan pada Gambar 6.

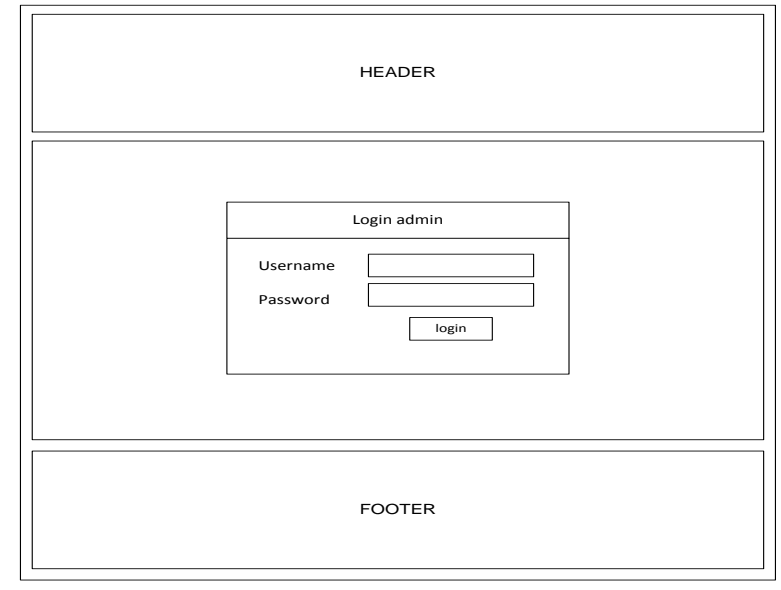

Gambar 6. Rancangan halaman login admin

\section{Halaman Menu Profil}

Halaman menu profil digunakan admin untuk mengedit, menambah atau menghapus data-data profil dengan rancangan sebagaimana terlihat pada Gambar 7.

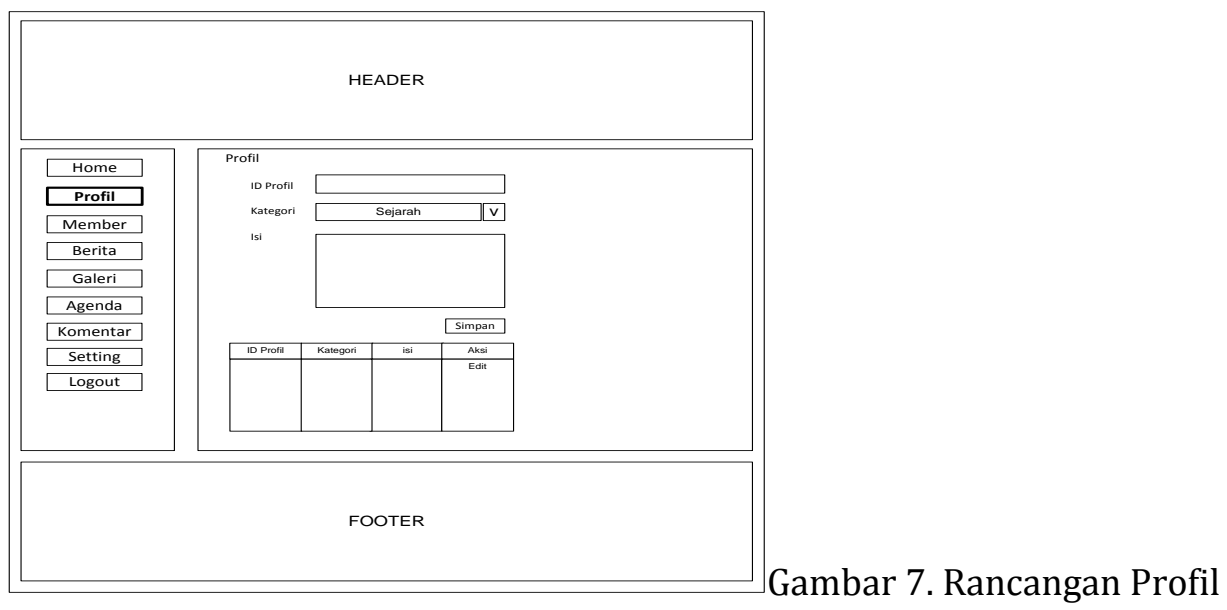

\section{Halaman Member}

Halaman ini hanya bisa diakses oleh member atau user khusus yang telah mendaftar di website IPMSY seperti pelajar dan mahasiswa yang berasal dari Sumbawa. Tiap member akan memiliki 
username dan password untuk dapat login ke halaman ini. Bila login benar maka akan masuk ke halaman member, jika salah maka akan muncul peringatan kesalahan dan meminta user untuk melakukan login ulang.

\section{Halaman Login Member}

Gambar 8 menunjukkan rancangan halaman login yang digunakan oleh member sehingga bisa masuk ke halaman member.

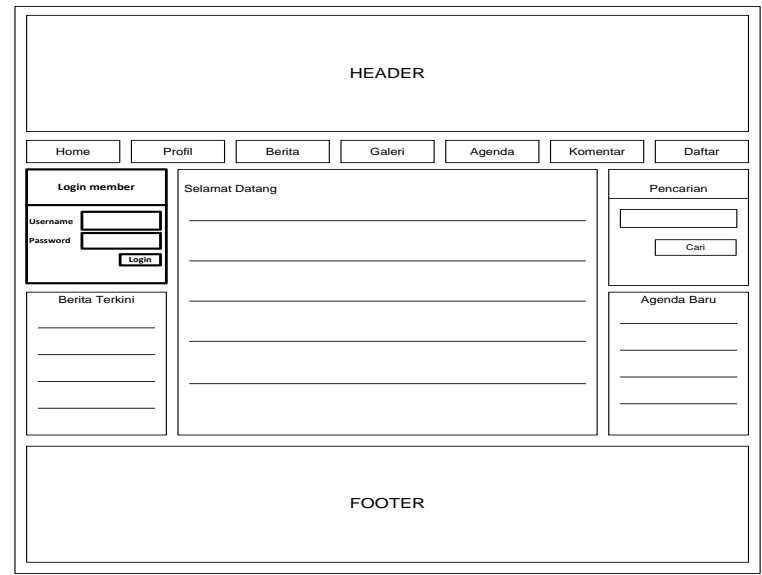

Gambar 8. Rancangan halaman login member

\section{Halaman EditData Member}

Untuk mengedit data member dapat dilakukan pada halaman edit member dengan rancangan yang ditunjukkan Gambar 9.

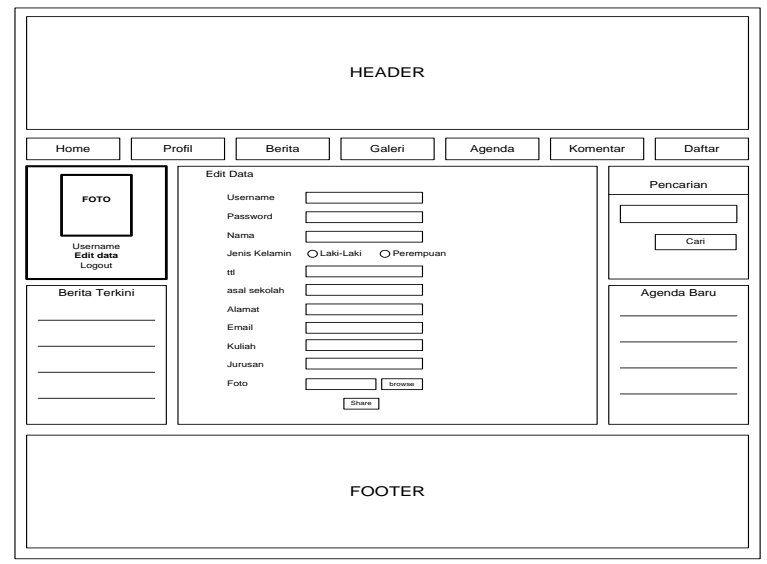

Gambar 9. Rancangan halaman edit data member

\section{Halaman Pengunjung}

Halaman pengunjung adalah halaman bagi pengunjung biasa. Pengunjung hanya bisa melihat informasi mengenai IPMSY seperti profil, berita, agenda, dan memberikan komentar. Tetapi pengunjung juga dapat menjadi member yaitu dengan cara mendaftarkan identitas diri langsung di website IPMSY dengan syarat harus pelajar atau mahasiswa yang berasal dari Sumbawa.

\section{Halaman Daftar}

Halaman daftar ini digunakan pengunjung bagi yang ingin mendaftar menjadi member.

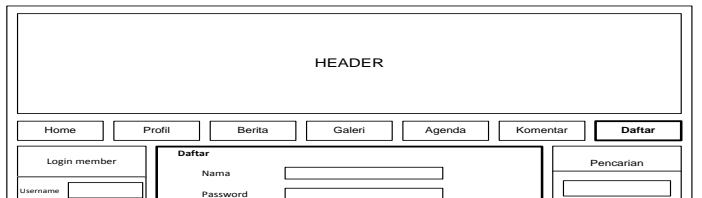




\section{Gambar 10. Halaman daftar pengunjung}

\section{Halaman Home}

Halaman home ini digunakan untuk tampilan home pengunjung.

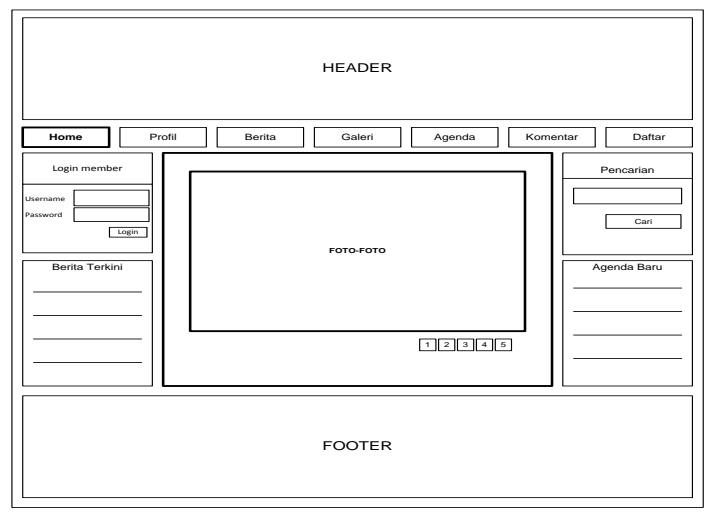

Gambar 11. Halaman home pengunjung

\section{IMPLEMENTASI DAN PEMBAHASAN}

\section{Implementasi}

Implementasi merupakan tahap meletakkan sistem yang baru dikembangkan agar nantinya sistem tersebut siap untuk dioperasikan sesuai dengan yang diharapkan. Tujuan dari tahap implementasi adalah menyiapkan semua kegiatan penerapan sistem sesuai dengan rancangan yang telah ditentukan.

\section{Implementasi Database dan Tabel}

Pembuatan database dan tabel merupakan langkah awal yang selalu dilakukan dalam membangun basis data. Dimulai dengan langkah pembuatan database dan dilanjutkan dengan pembuatan tabel serta komponen attributnya (Gambar 12). Pembuatan database sistem pada perancangan situs IPMSY dibuat dengan menggunakan MySqI. 


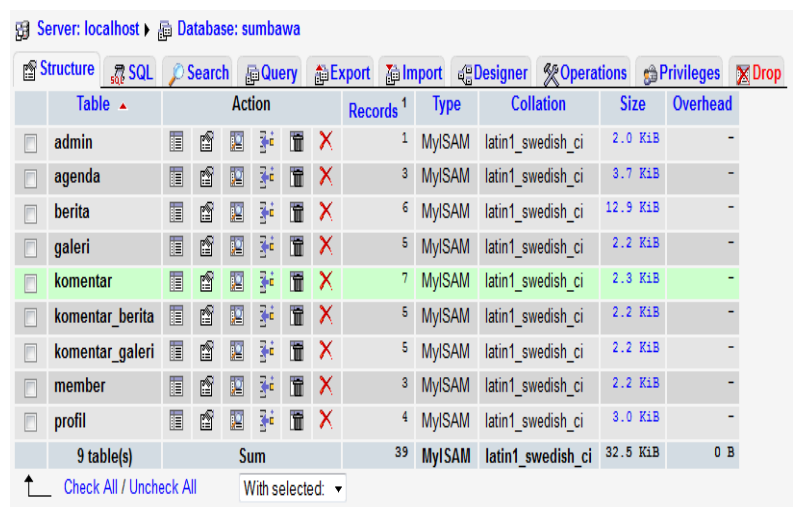

\section{Gambar 3.4 Login Admin}

Gambar 12. Struktur tabel

Berikut ini adalah tabel-tabel dari hasil perancangan:

1. Tabel Admin

Tabel admin digunakan untuk data admin pada website (Gambar 13).

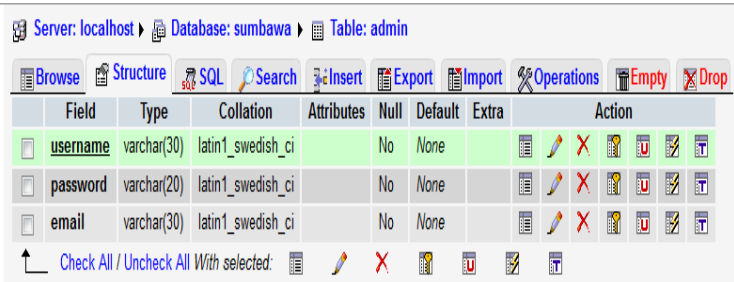

Gambar 13. Tabel Admin

2. Tabel Member

Tabel member (Gambar 14) digunakan untuk menyimpan dan mengelolah semua data member pada website.

\begin{tabular}{|c|c|c|c|c|c|c|c|c|c|c|}
\hline \multicolumn{2}{|c|}{ 霹Browse } & ucture $\mathrm{B}$ & QL $\rho$ Search & Fitinsert & 監Expor & it & & Q Operations & 5 蓜Empty & Drop \\
\hline & Field & Type & Collation & Attributes & es Null & Default & Extra & \multicolumn{3}{|c|}{ Action } \\
\hline 目 & id member & char(5) & latin1_swedish_ci & & No & None & & 霜 & X 闻 & 娄 园 \\
\hline 田 & username & varchar(50) & latin1_swedish_ci & & No & None & & 箱 & X 露 回 & 圂 \\
\hline 口 & nama & varchar(30) & latin1_swedish_ci & & No & None & & 霜 & 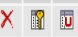 & 国国 \\
\hline$\square$ & password & varchar(20) & latin1_swedish_ci & & No & None & & 榎 $8 \gamma$ & X 江 & 易 园 \\
\hline Q & jk & char(1) & latin1_swedish_ci & & No & None & & 䀧 & × 䦛 & 橉 \\
\hline$\square$ & tII & varchar(30) & latin1_swedish_ci & & No & None & & 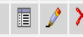 & $\times$ 盛 & 国 园 \\
\hline 目 & asal__sekolah & varchar $(30)$ & latin1_swedish_ci & & No & None & & 箱 & $x$ 昰 & 橉 娄 \\
\hline ] & alamat & varchar(30) & latin1_swedish_ci & & No & None & & 融 & 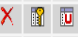 & 桜 \\
\hline 回 & email & varchar(30) & latin1_swedish_ci & & No & None & & 嘈 & $x$ 䫆 & 橉 囯 \\
\hline 田 & kuliah & varchar $(30)$ & latin1_swedish_ci & & No & None & & 霜 & $\mathrm{X}$ 问 & 類 囯 \\
\hline 目 & jurusan & varchar(30) & latin1_swedish_ci & & No & None & & 笽 $>>$ & X 闻 & 圆 \\
\hline ] & foto & varchar(30) & latin1_swedish_ci & & No & None & & 艦 $>\gamma$ & 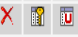 & 橉 娄 \\
\hline
\end{tabular}

Gambar 14. Tabel member

\section{Implementasi Interface}

Interface yang telah dirancang kemudian diimplementasikan dengan tampilan tiap halaman pada website: 


\section{Bagian Admin}

Tampilan halaman login admin ditunjukkan pada Gambar 15, sedangkan Gambar 16 menampilkan menu halaman home admin.

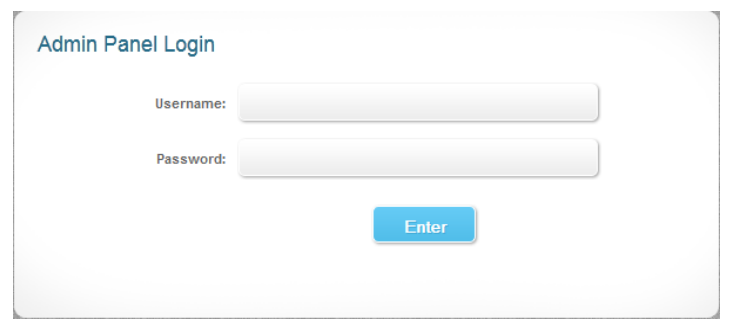

Gambar 15. Halaman login admin

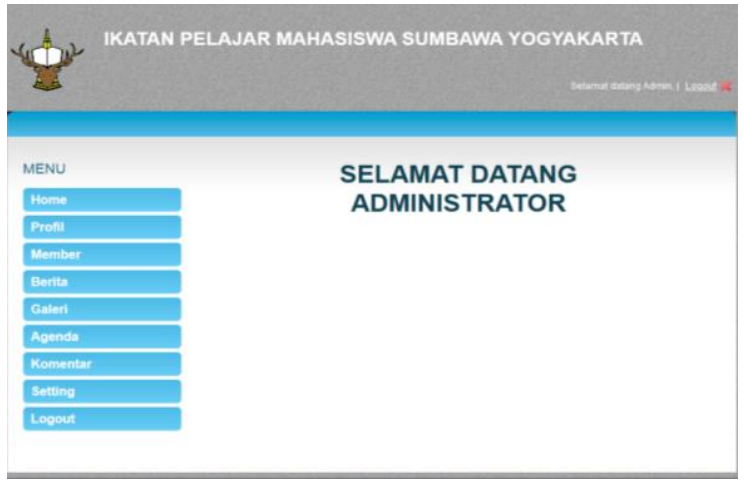

Gambar 16. Halaman home admin

\section{Halaman Menu Member}

Untuk mengelola data member, admin membutuhkan halaman menu member sehingga jumlah member yang tergabung dalam situs IPMSY dapat terdata dengan baik. Halaman menu member digunakan admin untuk mengelola, menambah, mengedit dan menghapus data member (Gambar 17).

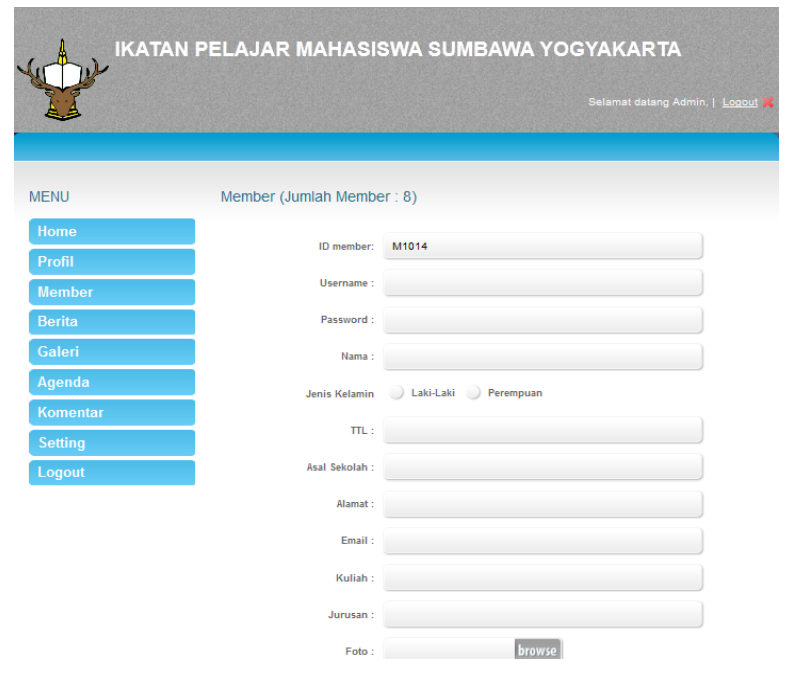


Gambar 17. Halaman menu member

\section{Bagian Member}

Rancangan interface bagian member diimplementasikan dalam bentuk halaman login member (Gambar 18) dan halaman member yang digunakan untuk mengedit data (Gambar 19).

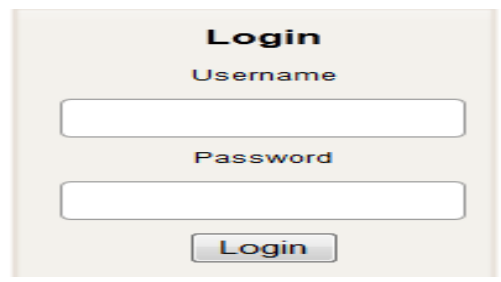

Gambar 18. Halaman login member

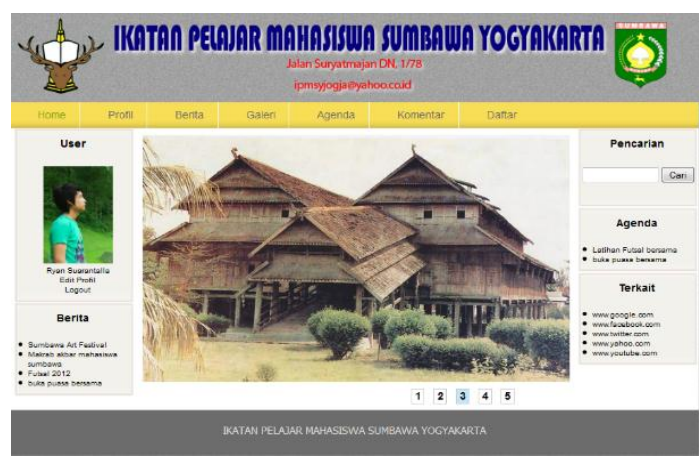

Gambar 19. Halaman member

\section{Bagian Pengunjung}

Gambar 20 merupakan tampilan yang digunakan sebagai homebagi pengunjung. Kemudian, bagi pengunjung yang ingin bergabung sebagai member, juga disediakan halaman untuk melakukan registrasi anggota (Gambar 21).

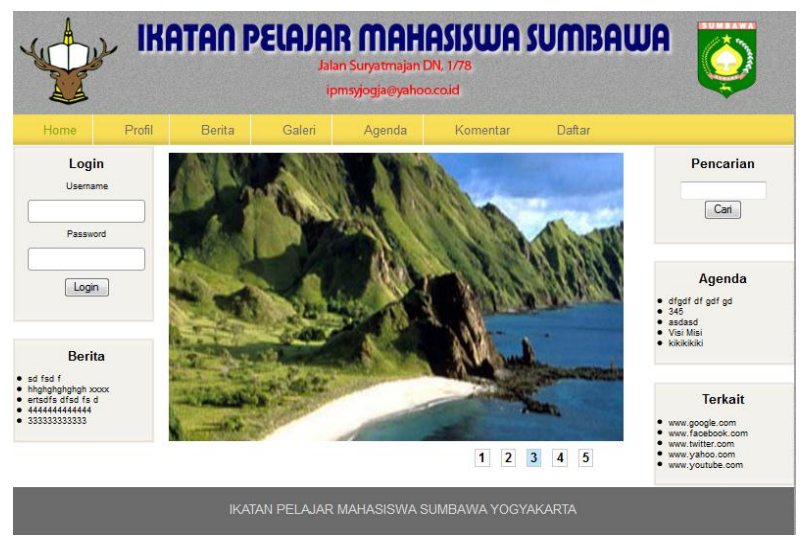

Gambar 20. Halaman home pengunjung 


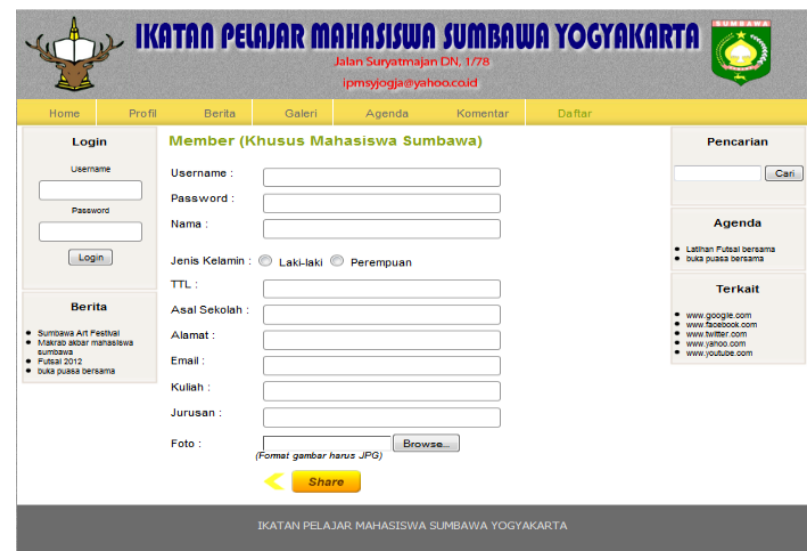

Gambar 21. Halaman daftar member

\section{Pembahasan}

\section{Listing Program}

Pada bagian listing program (script), akan dibahas pada bagian-bagian tertentu saja, yaitu listing program pada koneksi ke database dan validasi login member administrator.

Agar dapat mengakses sebuah database MYSQL, dalam sebuah aplikasi berbasis web maupun WAP terlebih dahulu harus dikoneksikan. Proses koneksi dan login member terhadap database ini menggunakan $P H P$.

\section{Pengujian Program}

Uji coba sistem dan program dalam Pembuatan Website IPMSY Ini akan dilakukan dengan pengetesan fungsi dan logika yang telah di berikan pada masing-masing program atau modul, apakah masih ada kesalahan atau tidak dengan Gmenjalankan program dapat dideteksi kesalahan yang ada dan fungsi-fungsi yang tidak sesuai. Kesalahan yang terjadi dan berakibat program tidak dapat berjalan sebagaimana mestinya adalah kesalahan sintaks. Pesan kesalahan ini akan muncul di browser ketika ada sintaks yang tidak benar.

\section{Black Box Testing}

Pengujian Black Box Testing ini dilakukan terhadap seluruh atau salah satu dari field yang ada, untuk mencari kesalahan, sehingga apabila ditemukan kesalahan bisa dilakukan perbaikan. Berikut adalah pengujiannya:

\section{Field yang diuji:}

\section{Login Member}

Pengujian username dan password yang dikosongkan atau di salahkan. Hasil ditunjukkan pada Gambar 22.

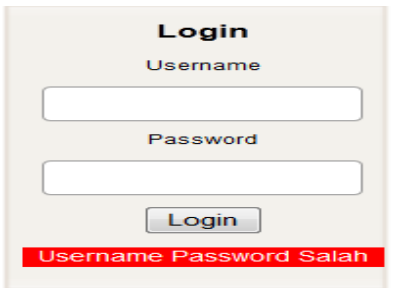

Gambar 22. Hasil pengujian member 


\section{Login Admin}

Pengujian username dan dan password yang dikosongkan atau di salahkan (Gambar 23).

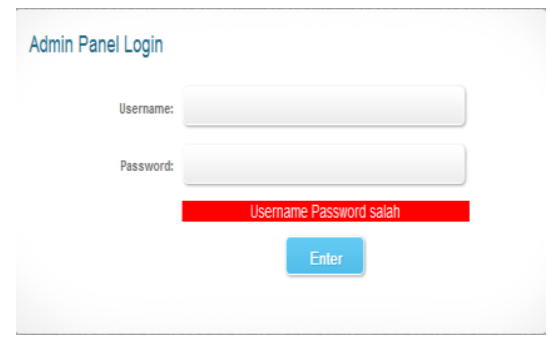

Gambar 23. Hasil pengujian admin

\section{Daftar Member}

Pengujian Data tidak terisi lengkap atau data dikosongkan. Jika terdapat data yang belum diisi akan muncul tampilan peringatan seperti yang ditunjukkan Gambar 24.

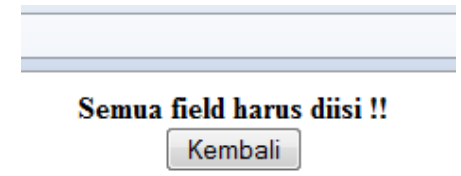

Gambar 24. Hasil daftar member

\section{White Box Testing}

Black Box Testing adalah pengujian semua logika dan fungsi, sedangkan White Box Testing adalah pengujian yang dilakukan terakhir sebelum sistem diimplementasikan.

Berikut adalah pengujian pada halaman agenda:

\begin{tabular}{l}
\hline Berita Galeri Agenda Komentar Daftar \\
\hline Agenda \\
Fatal error: Call to undefined function mysql_fetch_asoc() in C:Ixampplhtdocslsumbawalp_agenda.php on line 10
\end{tabular}

Gambar 24. Pengujian white box

\section{KESIMPULAN}

Dari hasil penelitian dan analisis yang telah dilakukan dalam pembuatan website, Maka dapat ditarik kesimpulan sebagai berikut:

1. Pada sistem baru memberi kemudahan bagi petugas organisasi untuk mendata mahasiswa dan sebagai media informasi bagi mahasiswa Sumbawa yang berada di Yogyakarta.

2. Dengan adanya sistem baru memberikan fasilitas berupa Menu Berita agar pengurus organisasi dengan mudah menyampaikan segala berita tentang akademik, kegiatan sosial mahasiswa ataupun yang lainnya, serta Menu Komentar untuk membantu berinteraksi dengan pengurus maupun mahasiswa se-sumbawa dan terdapat juga galeri foto-foto kegiatan mahasiswa sumbawa selama di Yogyakarta.

3. Website ini dapat diterapkan sesuai kebutuhan yang ada. Proses pendataan dapat dilakukan oleh petugas (admin) ataupun langsung dari mahasiswa sedangkan informasi dapat di akses oleh admin dan member untuk masyarakat umum kapanpun dan dimanapun. 


\section{DAFTAR PUSTAKA}

Al Fatta, Hanif , 2007. Analisis dan Perancangan Sistem Informasi. Andi Offset. Yogyakarta.

Arief, M.Rudyanto. 2006. Pemrograman Basis Data Menggunakan Transact-SQL dengan Microsoft SQL Server 2000. Andi Offset. Yogyakarta.

Arief, M.Rudyanto. 2011. Pemrograman Web Dinamis Menggunakan PHP dan Mysql. Andi Offset. Yogyakarta.

Jogiyanto, H.M. 1999. Analisis dan Desain Sistem Informasi. Andi Offset, Yogyakarta.

Kadir, Abdul. 2005. Dasar Pemrograman Web dengan ASP. Andi Offset. Yogyakarta.

Kusrini, M.Kom. 2007. Konsep dan Aplikasi Sistem Pendukung Keputusan. Andi Offset. Yogyakarta.

Madcoms, Andi. 2010. Adobe Dreamweaver CS5 dengan Pemrograman PHP-MySQL. Andi Offset. Yogyakarta.

Sismoro, Heri. 2005. Pengantar Logika Informatika, Algoritma, dan Pemrograman Komputer. Andi Offset. Yogyakarta.

Suyanto, M. 2005. Pengantar Teknologi Informasi Untuk Bisnis. Andi Offset. Yogyakarta.

Tata, Sutabri. 2005. Sistem Informasi Manajemen. Andi Offset. Yogyakarta. 